\title{
Introduction to Part 6
}

The previous parts have examined various later medieval theories of animal rationality. Such theories, it has been said, mainly arose from the grey areas of the Aristotelian model of the soul and its implicit definition of the animal/ human boundary. According to this definition, humans are rational animals. They are rational, first and foremost, because they are endowed with rational faculties, namely, intellect and reason. Second, they are rational because these faculties enable them to engage in rational or intellectual processes such as concept formation, judging, and reasoning. It is this triad of intellectual operations that shapes the way in which humans perceive and interact with the world. In many cases, humans behave rationally because their behaviour is based on a rational cognitive process. For instance, before taking our dog out for a walk we have reasoned that it is a good thing to do so because otherwise it might ruin the carpet. Theories of animal rationality, however, concern the question of whether this is something only we can do. Why should one assume that our dog cannot do this? Why should one assume that it is completely nonrational? If it is non-rational how can one explain that it gets excited about all sticks, and so seems to generalise? Or that it falls prey to sensory illusions, and so seems to judge? Or that it takes a detour in order to get around an obstacle, and so seems to reason?

It is questions like these to which theories of animal rationality try to provide an answer, and since late medieval thinkers obviously dealt with such questions it makes sense to say that they developed such theories. What remains to be seen, however, is how their theories compare to the theories of our own age. The commonly accepted narrative has it that later medieval theories differ radically from contemporary theories of animal rationality. Many would even say they differ to such a degree that there is no medieval analogue or predecessor of contemporary theories of this kind at all. Whether or not this is the case will be the subject of this last part. It will begin by sketching the differences that exist (Chapter 30), among the most important of which surely is that later medieval theories were developed within the framework of Aristotelian psychology. Although Aristotle's model of the soul is no longer seriously defended by anyone in contemporary animal psychology, there is a certain continuity between later medieval and contemporary theories in the sense that they usually deal with the question of how to describe the cognitive processes that underlie a certain behaviour (Chapter 31). Apparently, this can be done in many different ways which is why there exist not just one, but many theories of animal rationality. In other words, there are different answers to the 
question of whether those cognitive processes are radically different or quite similar in human and nonhuman animals. Those who claim that they are radically different are called 'differentialists' in contemporary animal philosophy. 'Assimilationists', by contrast, are those who focus on the similarities rather than the differences. To be clear, assimilationists and differentialists agree that there are both differences and similarities. Still, they disagree on whether the former outweigh the latter or vice versa.

This disagreement is something one can also find among later medieval authors (Chapter 32). As various examples show, they adopted different strategies when trying to account for the cognitive processes that underly a certain behaviour. While some considered those processes to be radically different, others stressed the similarities that exist between human and nonhuman animal cognition. This in itself is not much of a surprise because there is hardly any topic on which later medieval thinkers spoke with one voice. What is surprising is that some of them seriously considered the option of what could be called 'rationality without reason' (Chapter 33). This means that they in some sense dissolved the link between faculty and process rationality that usually characterises the medieval concept of rationality. For instance, they claimed that a process, such as reasoning, that was usually taken to require a rational faculty, can also be engaged in without this faculty.

There are, of course, important differences between rationality with and without reason but what is interesting to see is that the latter very much resembles the kind of practical and domain-specific rationality that is attributed to nonhuman animals in the contemporary debate. Besides the richness of the theoretical landscape in the later Middle Ages that is often ignored, this particular theoretical option establishes an interesting connection between later medieval and contemporary theories of animal rationality. Yet, before we can begin to closely examine this connection and the parallels between the theories of different periods it is necessary to briefly look at the differences that exist between thirteenth- and fourteenth-centuries theories and contemporary theories of animal rationality. 